\title{
ANALISIS PENGGUNAAN MEDIA PEMBELAJARAN APLIKASI KINEMASTER DI ERA PASCA NEW NORMAL PADA MATERI GREETING EXSPRESSION DI SMPN 3 CIPEUCANG
}

\author{
Eneng Liah Khoiriyah ${ }^{1}$, Ajeng Muliyasari ${ }^{2}$, Dede Imtihanudin ${ }^{3}$ \\ 1,2,3 STKIP Syekh Manshur, Pandeglang, Indonesia \\ 'Nengkhoir03@gmail.com, 2ajengmulyasari@gmail.com, ${ }^{3}$ dedeimtihanalbantani@gmail.com
}

\begin{abstract}
ABSTRAK
Penelitian ini berfokus kepada analisis penggunaan media pembelajaran Aplikasi KineMaster Di era Pasca New Normal pada materi greeting Exspression. Yang bertujuan Untuk mempermudah guru atau pendidik dalam menyampaikan materi kepada siswa khususnya pada era pasca new normal. Sebagai salah satu media untuk menyampaikan materi dengan menggunakan aplikasi KineMaster khususnya materi greeting exspression di era Pasca New Normal. Dapat memberikan motivasi kepada sisawa melalui vidio pembelajaran yang menarik yang di sajikan. Penelitian ini merupakan penelitian kualitatif deskriptif, dengan teknik pengumpulan data yaitu observasi, wawancara, dan, dokumen. Metode penyebaran angket digunakan untuk memperoleh data tentang bagaimana kepuasan peserta didik dalam penyampaian materi melalui media pembelajaran dalam aplikasi KineMaster. Metode observasi digunakan untuk mengetahui sikap dan karakterstik siswa pada era pasca new normal saat kegiatan pembelajaran bahasa inggris serta faktor-faktor yang dapat mempengaruhi proses pembelajaran. Metode wawancara dilakukan untuk mengetahui hasil nilai siswa ketika pembelajaran bahasa inggris materi greeting exspression dengan menggunakan media pembelajaran. Adapun hasil dari penelitian ini adalah siswa memiliki respon yang baik dapat dibuktikan dengan hasil analisis qusioner tentang kepuasan dengan nilai 89.66 dan pemahaman pembelajaran greeting ekspresion melalui video pembelajaran aplikasi KineMaster diperoleh rata-rata mendapatkan nilai 90.
\end{abstract}

Kata Kunci: vidio pembelajaran, greeting ekspression

\section{ANALYZING THE USE OF KINEMASTER APPLICATION IN THE POST NEW NORMAL ERA ON THE MATERIAL OF GREETING EXPRESSIONS AT SMPN 3 CIPEUCANG}

\begin{abstract}
This study focused on the analysis of the use of KineMaster Application learning media in the Post New Normal era on the material about Greeting Expression which aimed to make it easier for teachers or educators to convey material to students, especially in the post-new normal era. As a medium to convey material, the KineMaster application, especially for Greeting Expressions material in the Post New Normal era, increased students motivation through interesting learning videos. This research was descriptive qualitative research, in which the data were collected through observation, interviews, and documents. The questionnaire was distributed to obtain data about students' satisfaction about the material delivery through the KineMaster application. Meanwhile, the observation was used to determine the students' attitudes and characteristics in the post-new normal era during English learning activities and the factors affecting the learning process. Then, the interview was conducted to determine the results of students' scores through this learning media. The results of this study revealed that students showed good response as evidenced by the results of the questionnaire analysis about satisfaction with a value of 89.66 and understanding of greeting expression learning through the KineMaster application learning video obtained an average score of 90.
\end{abstract}

Keywords: learning media, greeting ekspression

\begin{tabular}{|c|c|c|}
\hline Submitted & Accepted & Published \\
\hline 15 September 2021 & 12 November 2021 & 27 November 2021 \\
\hline
\end{tabular}

\begin{tabular}{|l|c|c|}
\hline Citation & $:$ & $\begin{array}{r}\text { Khoiriyah, E.L., Muliyasari, A., \& Imtihanudin, D. (2021). Analisis Penggunaan Media Pembelajaran Aplikasi } \\
\text { Kinemaster Di Era Pasca New Normal Pada Materi Greeting Exspression Di Smpn 3 Cipeucang. Jurnal PAJAR } \\
\text { (Pendidikan dan Pengajaran), 5(6), 1773-1780. DOI : http://dx.doi.org/10.33578/pjr.v5i6.8562. }\end{array}$ \\
\hline
\end{tabular}

\section{PENDAHULUAN}

Perkembangan teknologi yang sangat cepat berbanding lurus dengan perkembangan sosial media. Hal ini berdampak pada proses belajar peserta didik didalam kelas. Menurut
McGraw- Hill, Presiden Pendidikan Tinggi, belajar secara efektif dengan jenis teknologi yang tepat adalah salah satu cara terbaik untuk memastikan siswa berhasil didalam kelas, selain 
itu sikap fokus peserta didik juga menjadi kuncinya. Hal ini dijelaskan oleh (Belardi 2013) dalam bukunya Texting While Studying: New Study from McGraw-Hill Education Reveals That Technology Can Be Students' Best Friend and Worst Enemy" Media pembelajaran diartikan segala sesuatu yang dapat digunakan untuk menyalurkan pesan (message), merangsang pikiran, perasaan, perhatian dan kemauan siswa sehingga dapat mendorong proses belajar mengajar.

Media pembelajaran merupakan gabungan antara bahan belajar dengan alat belajar dan merupakan bagian dari sumber belajar untuk dijadikan sebagai penyampai pesan dan informasi dalam pembelajaran (Muhson, 2010). Agar tujuan pembelajaran dapat tercapai secara maksimal serta meningkatkan efektivitas hasil pencapaian (Dewi, Murtinugraha \& Arthur, 2018). Selain itu, media pembelajaran juga dapat digunakan untuk meningkatkan proses dan hasil belajar dalam pembelajaran (Ayu, Arthur \& Neolaka, 2019). Pemanfatan dan perancangan media pembelajaran dengan baik akan membantu peserta didik dalam memahami materi pembelajaran. (Ali, 2010) Fungsi media pembelajaran adalah membantu memudahkan belajar siswa dan juga memudahkan proses pembelajaran bagi guru, memberikan pengalaman lebih nyata, menarik perhatian siswa lebih besar, semua indera dapat diaktifkan, dapat membangkitkan dunia teori dengan realitanya.

Di jelaskan kembali oleh (Andini, Amaliah, Ariyansyah, 2021) dalam penelitiannya tentang Pengaruh Penggunaan Media Pembelajaran bahwa Media pembelajaran memiliki peran yang sangat penting untuk menyampaikan dan memperjelas penyajian pembelajaran dan memungkinkan proses belajar mengajar lebih bervariasi dan bergairah. Hal ini sesuai dengan pernyataan Sukiman (Sukiman, 2012), menyatakan bahwa media pembelajaran dapat mempermudah penyajian pesan dan informasi terhadap peserta didik sehinga dapat memperlancar, meningkatkan proses belajar mengajar dan hasil belajar. Dalam proses belajar dan pembelajaran guru harus pintar dalam memilih media pembelajaran yang akan digunakan (Erlin. K Tobamba, Eko Siswono, 2019). Pemilihan media pembelajaran yang baik harus menjadi perhatian seorang tenaga pendidik dalam hal ini adalah guru yang diharapkan mampu meningkatkan hasil belajar siswa.

Dalam penjelasan di atas peneliti dapat menyimpulkan bahwa peran media pembelajaran sangat penting untuk proses belajar mengajar siswa hal ini bertujuan untuk mengetahui tingkat pemahaman siswa dalam proses pembelajaran, menarik perhatian siswa serta dapat memberikan motivasi yang baik bagi siswa. pemilihan media pembelajaran juga mempunyai peran yang sangat penting khususnya pada masa era new normal. Karena menurut (Handhika, 2012) Penggunaan media pembelajaran yang tidak interaktif, tidak menarik akan membuat peserta didik sulit meningkatkan motivasi belajarnya, maka media pembelajaran yang digunakan harus interaktif serta menarik untuk menghasilkan prestasi peserta didik yang baik. (Ting-Hung, Chi-Yang, JenHwang, Chu, Wang, 2018)

Aplikasi pembelajaran daring merupakan solusi bagi siswa dalam proses pembelajaran yang tanpa dibatasi oleh ruang dan waktu yang pada sisi lain siswa dituntut untuk mempelajari banyak materi dan mengerjakan tugas yang bertumpuk dari guru.

Pembelajaran daring merupakan pembelajaran yang menggunakan jaringan internet dengan aksesibilitas, konektivitas, fleksibilitas, dan kemampuan untuk memunculkan berbagai jenis interaksi pembelajaran. Kemudian, pada penelitian Zhang et al., (2004) menunjukkan bahwa penggunaan internet dan teknologi multimedia mampu merombak cara penyampaian pengetahuan dan dapat menjadi alternatif pembelajaran yang dilaksanakan dalam kelas tradisional. Dari penjelasan teori dan penelitian diatas, menunjukkan pembelajaran daring dapat menjadi alternatif pembelajaran yang dilakukan secara luring.

Aplikasi pembelajaran daring merupakan solusi bagi siswa dalam proses pembelajaran yang tanpa dibatasi oleh ruang dan waktu yang pada sisi lain siswa dituntut untuk mempelajari banyak materi dan mengerjakan tugas yang bertumpuk dari guru . Dengan prinsip fleksibel, siswa mendapatkan materi dan informasi terbaru bahkan bisa jadi informasi yang diperoleh siswa melebihi guru karena di era sekarang ini informasi sangat 
mudah diperoleh siapa saja. Beberapa aplikasi yang dapat membantu terlaksananya kegiatan pembelajaran secara daring, di antaranya ada WhatsApp Grup, Zoom, Edmodo, Surat Elektronik, Google Classrom, Schoology dan lain sebagainya (Septiani \& Setyawati, 2020)

Dalam hal ini peneliti menggunakan media pembelajaran berbasis video yang bertujuan untuk mempermudah siswa mendapatkan materi serta mempermudah guru menyampaikan materi serta dapat memberikan fiture-fiture menarik yang dapat memotivasi siswa dalam pembelajaran.

Salah satu aplikasi yang dapat dimanfaatkan dalam pembuatan bahan ajar berbasis multimedia berupa video adalah KineMaster. Kinemaster merupakan aplikasi mobile yang secara khusus dirancang untuk membantu pengguna Android dan Ios dalam memodifikasi video, dari video biasa menjadi video yang lebih menarik. Aplikasi ini memudahkan pengguna melakukan editing video dengan semua tools yang sudah disediakan di menu tampilan. Dengan hanya beberapa sentuhan, pemaduan tema, animasi, dan efek dapat menghasilkan sebuah karya imajinasi layaknya seorang editor video profesional. Salah satu usaha untuk mewujudkan terciptanya kompetensi yang baik adalah pembuatan bahan ajar berbasis online.

Selain itu dengan adanya pembelajaran daring pada era new normal khususnya dinasa Pendidikan pandeglang mengintruksikan kepada seluruh guru untuk membuat video pembelajaran dengan menggunakan aplikasi yang mudah di gunakan oleh guru di antaranya aplikasi KineMaster

Dalam pembelajaran bahasa inggris materi greeting exspression di era pasca new normal kelas VII SMPN 3 Cipeucang perlu adanya vidio dan bahan ajar yang baik dalam penyampaian materi. Bahan ajar adalah segala bentuk konten baik teks, audio, foto, video, dan animasi yang dapat digunakan untuk belajar. (Fajar, Ibnu. 2010)Bahan ajar berbasis multimedia adalah bahan ajar yang disusun dan dikembangkan dengan menguunakan alat bantu TIK untuk mengolah data, termasuk memproses, mendapatkan, menyusun, menyimpan, dalam berbagai cara untuk menghasilkan informasi yang berkualitas.

\section{KAJIAN TEORETIS \\ Pengertian Media Pembelajaran}

Kata media merupakan bentuk jamak dari kata medium. Medium dapat didefinisikan sebagai perantara atau penerima atau pengantar terjadinya komunikasi dari pengirim menuju penerima. Media merupakan salah satu komponen komunikasi, yaitu sebagai perantara pembawa pesan dari komunikator menuju komunikan (Indriana, Dina. 2011). Menurut Ali media pembelajaran diartikan segala sesuatu yang dapat digunakan untuk menyalurkan pesan (message), merangsang pikiran, perasaan, perhatian dan kemauan siswa sehingga dapat mendorong proses belajar mengajar (Ali, Muhammad, 2010). Media sebagai teknik yang digunakan dalam rangka lebih mengefektifkan komunikasi antara guru dan murid dalam proses pendidikan dan pembelajaran di sekolah (Musfiqon, 2012). Sedangkan menurut Sadiman media pembelajaran bisa diartikan sebagai pesan, sumber, saluran, dan penerima pesan adalah komponen-komponen proses komunikasi. Pesan yang disampaikan adalah ajaran atau didikan yang ada dalam kurikulum. Sumber pesan bisa guru, siswa, buku dan media. Saluran/media yang digunaakn adalah media pembelajaran (Sadiman,AriefS.(dkk).2010).

Dari beberapa pendapat tersebut, dapat disimpulkan bahwa pengertian media pembelajaran adalah segala sesuatu yang dapat digunakan untuk menyalurkan pesan (bahan pembelajaran), sehingga dapat merangsang perhaitan, minat, dan peranan siswa dalam kegiatan belajar untuk mencapai tujuan belajar.

Kemudian, Pembelajaran daring yang dilakukan selama masa pandemi tentunya amat bergantung pada ketersediaan sarana dan prasarana online. Peran teknologi sangat penting untuk memfasilitasi dalam interaksi, berkomunikasi serta penyajian materi agar proses pembelajaran berjalan dengan baik (Thoms \& Eryilmaz, 2014). Oleh karena itu penting sekali memanfaatkan teknologi dengan semaksimal mungkin. Untuk mempermudah komunikasi antara pendidik dengan peserta didik maka peran dari media pembelajaran sangat dibutuhkan (Borisova dkk., 2016). Namun jika tidak dimanfaatkan dengan baik tentunya 
hanya akan dapat mengakibatkan tidak terlaksananya pembelajaran dengan efektif

\section{Manfaat Media Pembelajaran}

Manfaat praktis dari penggunaan media pembelajaran di dalam proses belajar mengajar adalah sebagai berikut: (1) media pembelajaran dapat memperjelas penyajian pesan dan informasi sehingga dapat memperlancar proses dan hasil belajar, (2) media pembelajaran dapat meningkatkan dan mengarahkan perhatian siswa sehingga dapat menimbulkan motivasi belajar, (3) media pembelajaran dapat menanggulangi keterbatasan indera, ruang, serta waktu, (4) media pembelajaran dapat memberikan kesamaan pengalaman kepada siswa tentang peristiwaperistiwa di lingkungan mereka (Arsyad, Azhar. 2009). Selain itu, kontribusi media pembelajaran menurut (Kemp and Dayton) adalah (1) penyampaian pesan pembelajaran dapat lebih terstandart, (2) pembelajaran dapat lebih menarik, (3) pembelajaran dapat lebih interaktif dengan menerapkan teori belajar, (4) waktu pelaksanaan pembelajaran dapat diperpendek, (5) proses pembelajaran dapat berlangsung kapanpun dan dimanapun, (6) sikap positif siswa terhadap materi pembelajaran serta proses pembelajaran ditingkatkan, (7) peran guru berubah kearah positif. Dari beberapa pendapat tersebut, dapat disimpulkan bahwa manfaat media pembelajaran dapat memperjelas pesan agar tidak terlalu verbalistis, mengatasi keterbatasan ruang, waktu, tenaga dan daya indera, menimbulkan gairah belajar serta memberikan rangsangan yang sama mempersamkan pengalaman dan menimbulkan presepsi yang sama.

\section{Fungsi Media Pembelajaran}

Fungsi media pembelajaran khususnya media visual menurut Levie,dkk adalah fungsi atensi, fungsi afektif, fungsi kognitif, fungsi kompensatoris. Sedangkan menurut Benni media pembelajaran berfungsi membantu memudahkan belajar siswa dan juga memudahkan proses pembelajaran bagi guru, memberikan pengalaman lebih nyata, menarik perhatian siswa lebih besar, semua indera dapat diaktifkan, dapat membangkitkan dunia teori dengan realitanya. Dari berberapa pendapat diatas, dapat disimpulkan bahwa fungsi media pembelajaran adalah untuk meningkatkan kualitas pembelajaran dengan indikator semua materi tuntas disampaikan dan peserta didik memahami secara lebih mudah dan tuntas

\section{METODE PENELITIAN}

Jenis penelitian ini adalah penelitian kualitatif. penelitian kualitatif menurut (Flick, Uwe. 2007) adalah penelitian yang diperuntukkan untuk memahami, menguraikan bahkan menjelaskan fenomena sosial yang ada dengan cara-cara sebagai berikut: (1) Dengan menganalisis pengalaman dari individu- individu atau kelompok (misalnya masyarakat). Pengalaman ini dapat berkaitan dengan sejarah hidup seseorang, pengetahuannya ataupun cerita yang berkaitan dengan hidupnya.(2) Dengan menganalisis interaksi dan komunikasi setiap individu atau kelompok. (3)Dengan menganalisis dokumendokumen (misalnya teks, gambar, film atau musik).

Subjek dalam penelitian ini adalah siswa kelas VII SMPN 3 Cipeucang yang berjumlah 60 orang dari 3 kelas, namun untuk penelitian ini hanya di ambil 15 orang, diambil dari masingmasing kelas VII yang berjumlah 3 kelas. Masingmasing kelas 5 orang di SMPN 3 Cipeucang. Adapun teknik pengumpulan data dengan observasi, wawancara, dan dokumen. Dalam penelitian kualitatif Instrumen utamanya adalah peneliti itu sendiri, data utama penelitian ini berupa video pembelajaran menggunakan aplikasi KineMaster dan analisis hasil observasi pola perilaku siswa selama proses pembelajaran online, yang meliputi kesiapan guru sebelum melaksanakan pembuatan video, pelaksanaan penyampaan materi pembelajaran, evaluasi dan tindak lanjut serta faktor atau kendala yang dialami siswa dan guru selama proses pembelajaran menggunakan media pembelajaran khususnya aplikasi KineMaster. Dalam implementasinya, penelitian qualitative dilakukan melalui tiga tahap atau proses yakni reduksi data (data reduction), pengorganisasian (organisation), dan interpretasi data (interpretation)[15]. Reduksi data adalah proses mengidentifikasi data mentah (raw data) yang telah diperoleh dengan melakukan langkah summary berdasarkan data-data yang ada 
di lapangan melalui wawancara, pengkodean (coding) dan kategorisasi(categorising). Pengorganisasian adalah proses mengumpulkan atau menyatukan informasi data yang dihasilkan dari identifikasi awal (proses reduksi data). Hasil analisis dari langkah reduksi data dan pengorganisasian tersebut selanjutnya dilakukan interpretasi data. Interpretasi data ini akan muncul sebuah kesimpulan.

Adapun cara pengambilan data menggunakan tringulasi sumber, dengan cara menyocokkan hasil observasi pertama, hasil wawancara pertama, hasil observasi pertama dan dokumen petama. Selanjutnya, hasil wawancara kedua dengan hasil observasi kedua, dokumen kedua, dan hasil wawancara ketiga dengan hasil observasi ketiga dan dokumen ketiga. Sehingga dari hasil pengambilan data sebanyak tiga kali tersebut diperoleh transkrip kegiatan khususnya dalam analsis penggunaan aplikasi KineMaster di era Pasca New normal. Kemudian data tersebut akan di deskripsikan dengan jelas sesuai dengan hasil penelitian.

\section{HASIL DAN PEMBAHASAN}

Langkah pertama penelitian ketika mengambil sampel data di SMPN 3 CipeucangPandeglang peneliti mecoba melakukan zoom meeting melibatkan siswa dan guru dengan menampilkan materi greeting ekspression melalui aplikasi KineMaster ternyata dalam hal ini banyak sekali kendala yang terjadi khususnya masalah sinyal yang terjadi di daerah tersebut. Sehingga yang mengikuti pembelajaran pun terhambat.

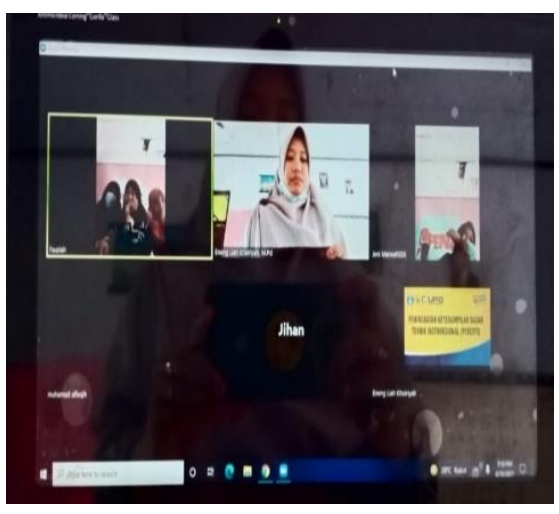

Gambar 1. Pembelajaran Zoom Meeting

Kemudian peneliti mencoba langkah lain tanpa menghilangkan prosese penyampaian materi dan proses belajar mengajar yaitu dengan cara membuat media pembelajaran melalui video menggunakan aplikasi KineMaster khususnya materi greeting ekspression yang di share melalui youtobe dan memberikan alamat link yang di berikan kepada siswa kelas VII. Hal ini sangat membantu memudahkan belajar siswa dan juga memudahkan proses. Pembelajaran bagi guru, memberikan pengalaman lebih nyata, menarik perhatian siswa lebih besar, semua indera dapat diaktifkan, dapat membangkitkan dunia teori dengan realitany . adapun aplikasi yang peneliti gunakan yaitu aplikasi Kinemaster. Aplikasi ini merupakan aplikasi mobile yang secara khusus dirancang untuk membantu pengguna Android dan Ios dalam memodifikasi video, dari video biasa menjadi video yang lebih menarik. Aplikasi ini memudahkan pengguna melakukan editing video dengan semua tools yang sudah disediakan di menu tampilan. Dengan hanya beberapa sentuhan, pemaduan tema, animasi, dan efek dapat menghasilkan sebuah karya imajinasi layaknya seorang editor video profesional. 


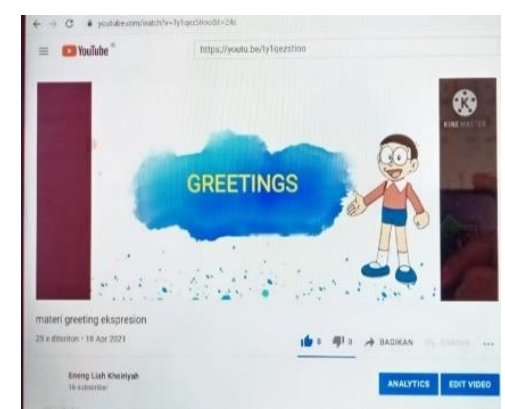

Gambar 2. Pembelajaran Melalui Aplikasi Kinemaster

Langkah ke dua peneliti menyebarkan angket questioner kepuasan terhadap siswa dalam pembelajaran materi greeting exspression dengan menggunakan Aplikasi KineMaster. Hal ini mendapatkan respon yang baik dari siswa karena terlihat dalam hasil penyebaran instrument yang diberikan oleh peneliti kepada siswa setelah melaksanakan proses belajar mengajar melalui aplikasi kinemaster materi greeting exsperssion di SMPN 3 Cipeucang dengan menggunakan sampel 15 orang siswa. Adapun hasil dari penyebaran angket dari hasil pengambilan data adalah:

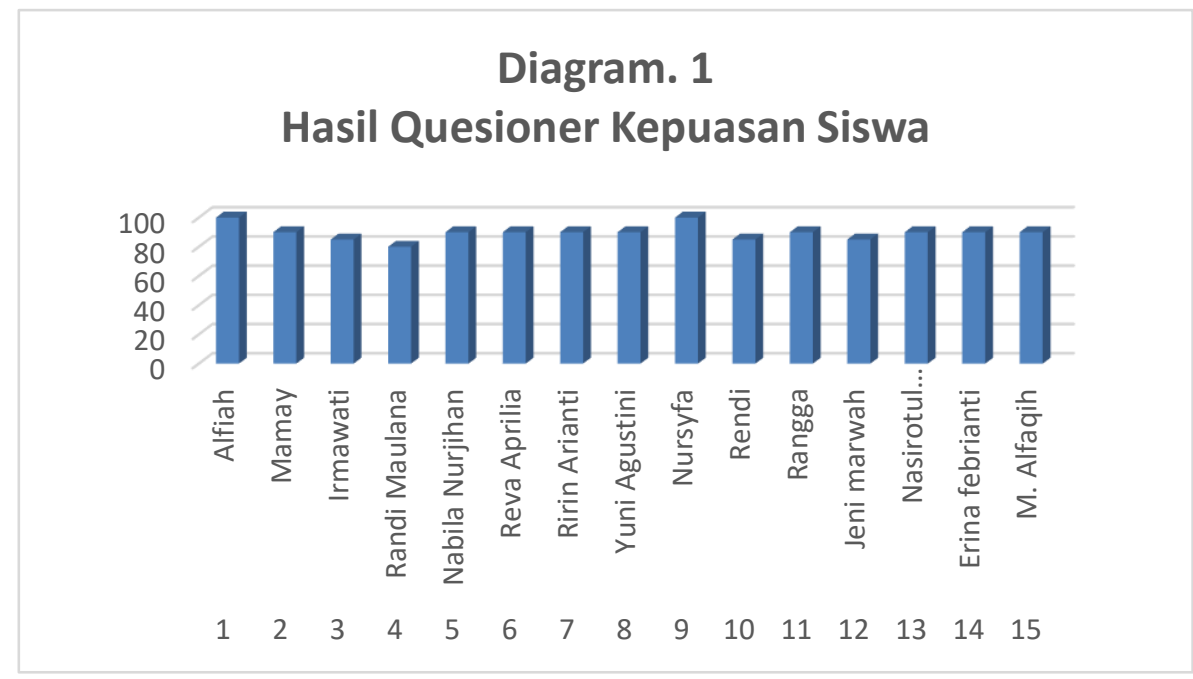

Gambar 3. Hasil Quesioner

Terlihat dalam diagram diatas hasil dari questioner kepuasan siswa dalam materi greeting expression yang berjumlah 20 butir questioner dengan proses penilaian. Peneliti melihat respon positive dari responden khususnya siswa karena mereka merasa termotivasi ketika belajar menggunakan aplikasi KineMaster. hal ini benar yang dikemukakan oleh ali Muhammad Media pembelajaran sangat membantu untuk menyalurkan pesan (message), merangsang pikiran, perasaan, perhatian dan kemauan siswa sehingga dapat mendorong proses belajar mengajar
(Ali, Muhammad. 2010). 15 siswa mendapatkan nilai diatas rata-rata bahkan ada 2 orang siswa mendapatkan presentase $100 \%, 9$ orang mendapatkan presentase $90 \%, 3$ orang siswa mendapatkan presentase $85 \%$, dan 1 orang mendapatkan nilai presentase $80 \%$ dengan nilai rata-rata 89.66 .

Langkah ke tiga peneliti memberikan soal berbentuk Pilihan Ganda untuk mengetahui sejauh mana pemahaman siswa terhadap materi greeting exspression hasil Tersebut peneliti mencoba membuat diagram. 


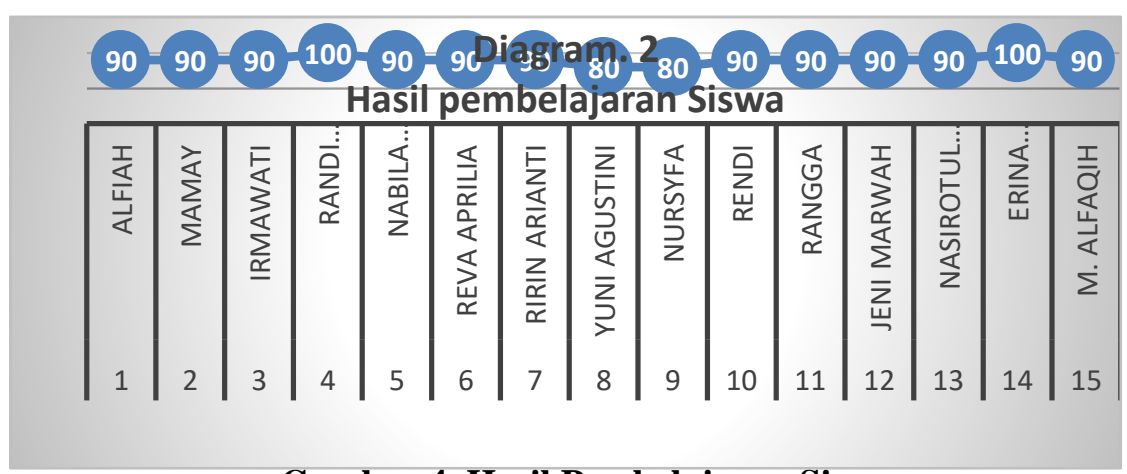

\section{Gambar 4. Hasil Pembelajaran Siswa}

Dari hasil diagram pembelajaran siswa menggunakan aplikasi KineMaster di atas terlihat perolehan nilai siswa yang sangat signifikan diatas yaitu 2 orang mendapatkan nilai 100,11 orang mendapatkan nilai 90,3 orang mendapatkan nilai 80 dengan nilai rata-rata 90.

Dari hasil nilai yang diperoleh siswa serta antusias siswa dalam pembelajaran Media pembelajaran menggunakan aplikasi KineMaster mendapatkan respon yang positive khususnya pada pembelajaran di era New Normal. Media pembelajaran juga merupakan alat yang digunakan untuk membantu proses pembelajaran agar tercipta pembelajaran yang efektif dan mencapai tujuan yang diharapkan. Media pembelajaran dengan menggunakan Aplikasi KineMaster ini merupakan salah satu alternatif dari pilihan untuk meningkatkan minat siswa dalam belajar Bahasa Inggris karena proses pembuatannya mudah dan dapat menyajikan video-video yang menarik serta dapat memeberikan motivasi secara langsung melalui content dan fiture-fiture yang ada di dalam Aplikasi KineMaster.

\section{SIMPULAN DAN REKOMENDASI}

Media pembelajaran memiliki peran yang sangat penting dalam proses belajar mengajar. media pembelajaran adalah segala sesuatu yang dapat digunakan untuk menyalurkan pesan (bahan pembelajaran), sehingga dapat merangsang perhatian, minat, dan peranan siswa dalam kegiatan belajar untuk mencapai tujuan belajar. Video pembelajaran merupakan salah satu media dalam belajar, melalui video siswa merasa tertarik untuk belajar dan termotivasi dalam content video tersebut. Aplikasi kineMaster merupakan sebuah aplikasi untuk mengedit video pembelajaran yang mudah digunakan, dengan fiture- fiture yang lengkap di dalamnya. Karena pada era new normal jarang sekali kita mengadakan pemebelajaran tatap muka maka strategi yang baik pada saat penyampaian materi yang menarik yaitu melalui video.

Dalam Analisis penggunaan Aplikasi Kinemaster Era New Normal Materi Greeting Exspression di SMPN 3 Cipeucang memiliki hasil yang positive terlihat dalam hasil instrument questioner kepuasan siswa terhadap pemeblajaran serta hasil pembelajaran siswa materi Greeting exspression menggunakan aplikasi Kine master memiliki nilai dia atas rata-rata 89.66 dan nilai rata-rata hasil pemahaman siswa terhadap materi greeting ekspression menggunakan aplikasi KineMaster pada Era New Normal di SMPN 3 Cipeucang dengan nilai 90.

\section{DAFTAR PUSTAKA}

Ajeng, M., \& Linda. (2020). Sikap dan Respon Anak PAUD dalam Mengenal Metamorfosis Serangga Melalui Media Animasi, Jurnal Obsesi : Jurnal Pendidikan Anak Usia Dini, 5(2), 10521051. DOI: 10.31004/obsesi.vxix.xxx.

Ali, M. (2010). Guru Dalam Proses Belajar Mengajar. Bandung: Sinar Baru Algensindo.

Arsyad, A. (2009). Media Pembelajaran. Jakarta: PT Raja Grafindo Persada.

Belardi. (2013). Texting While Studying: New Study from McGraw-Hill Education Reveals That Technology Can Be Students' Best Friend and Worst Enemy. McGrawHill Education.

Erlin, P., \& Nyoto, H. (2020). Efektivitas Penggunaan Media Pembelajaran Permainan Tradisional Congklak 
Jurnal PAJAR (Pendidikan dan Pengajaran)

Volume 5 Nomor 6 November | ISSN Cetak : 2580 - 8435 | ISSN Online : 2614 - 1337

DOI : http://dx.doi.org/10.33578/pjr.v5i6.8562

Terhadap Minat Belajar Matematika (Mtk) Siswa Sekolah Dasar. Jurnal Pendidikan Dasar Borneo (Judikdas Borneo), 01(02), $2685-9645$.

Fajar, I. (2010). Panduan Penyusunan Bahan Ajar Berbasis TIK, http://www

Flick, U. (2007). Designing qualitative research. London: SAGE

Fielding, J., dan Fielding, N. (2008). Synergy and synthetis: integrating qualitative and quantitative data. Dalam Alasuutari, Pertti., Bickman, Leonard., dan Brannen, Julia. Editor. The SAGE handbook of social research methods. London: SAGE. Hal.555-571

Hsing-chinLee. (2014). Social media and student learning behavior: Plugging into mainstream music offers dynamic ways to learn English. Computers in Human Behavior, 36, 496-501.

Indriana, D. (2011). Ragam Alat Bantu Media Pengajaran. Yogyakarta: DIVA Press.

Musfiqon. (2012). Pengembangan Media dan Sumber Pembelajaran. Jakarta: PT Prestasi Pustakaraya.

Naili, R., Fetro, M., Haryadi, D., \& Luriawati M, (2021). Analisis Penggunaan Media Audio Visual Interaktif Untuk Meningkatkan Pembelajaran Teks Cerpen. Jurnal Tuturan, 10(1), 20-30.

Nesi, A., Andini, K. A., \& Ariyansyah. (2021). Pengaruh Penggunaan Media Pembelajaran Berbasis Vectorian Giotto Terhadap Motivasi dan Hasil Belajar Siswa SDIT Di Kabupaten Oku Timur. Jurnal Bidang Pendidikan Dasar, 5 (1), 25-30

Nasser, O. (2012). The Importance of Media in Foreign Language Learning. Procedia Social and Behavioral Sciences, 5(4), 2428.

Irfan, M., \& Ariandi, A. (2021). Analisis Penggunaan Aplikasi Daring oleh Dosen Program Studi Pendidikan Biologi Universitas Sulawesi Barat selama Pandemi Covid-19. Jurnal Ilmu Pendidikan (JIP) STKIP Kusuma Negara, 12(2), 139-144.
Sadiman, A. S. (dkk). (2010). Media Pendidikan:Pengertian,Pengembangan, dan Pemanfaatannya. Jakarta: Alfabeta. 